\title{
Diabetes Mellitus: Protective in Development of ARDS
}

\section{Abhishek Singla', and Ariel M Modrykamien ${ }^{2 *}$}

${ }^{1}$ Department of Internal Medicine, Creighton University Medical Center, Omaha, USA

${ }^{2}$ Department of Medicine, Pulmonary, Sleep and Critical Care Medicine Division, Creighton University Medical Center, Omaha, USA

Despite improvement in survival in past decade, mortality in Acute respiratory distress syndrome (ARDS) still remains unacceptably high [1]. Moreover, physical, cognitive, and psychological disorders may last for months or years following recovery from acute illness in the survivors of ARDS. So far, except for lower tidal volumes, no other management modality has been universally accepted to improve outcomes of this devastating illness. Thus, prevention of ARDS to improve survival and long-term functional outcomes has been a major focus of research in past few years. Though a number of risk factors have been identified, diabetes mellitus has been shown to be protective in development of ARDS.

After a prospective, multicenter study of 113 individuals with septic shock which showed a $25 \%$ rate of ARDS in subjects with diabetes versus $47 \%$ in those without it ( $\mathrm{p}=0.03$ ) [2]; a large cohort study of 688 patients confirmed that diabetes was protective against the development of ARDS even after adjustment for potential confounders such as age, clinical risk for ARDS, severity of illness, and transfusion (adjusted odds ratio 0.58 ; 95\% confidence interval, 0.36-0.92) [3]. Finally, a third cohort study with 160 septic patients revealed that the rate of ARDS was $24 \%$ in diabetic individuals compared with $43 \%$ in non-diabetics [4]. Collectively from these three independent cohorts of critically ill patients, it was shown that the odds ratio for diabetes and ARDS ranged from 0.33 to 0.58 after adjusting for confounding variables [5]. In a recently developed Lung injury prediction score (LIPS) to identify patients at risk of developing ARDS, presence of diabetes mellitus was identified as the single negative predictor but was limited to patients with sepsis [6].

It is possible that a part of this effect may be secondary to a direct biological effect or secondary to fact that diabetics are more likelihood of having non-pulmonary sources of sepsis, thereby making them less likely to meet ARDS criteria. However, preclinical studies also suggests complex pathways that may be involving effects of hyperglycemia on the inflammatory response, metabolic abnormalities in diabetes and anti-diabetic medications that might be playing a role [5]. Effect of hyperglycemia is conflicting. On one hand, hyperglycemia can promote inflammation by increasing pro-inflammatory cytokines [7], increasing leukocyte adhesion molecules, promoting the procoagulant state $[8,9]$ as well as through inflammation and endothelial dysfunction induced by Advanced glycation end products (AGE) which in turn can promote ARDS [10]. However, on the other hand, hyperglycemia also impairs immunity by increasing production of anti-inflammatory cytokines like IL-10, mitochondrial dysfunction and impairment of neutrophil function which can be protective for lung injury [11].

Non-hyperglycemic mechanisms have also shown considerable effects in pathophysiology of ARDS. Animal models have exhibited substantially less microvascular protein extravasation after intratracheal instillation of lipopolysaccharide in diabetics compared with nondiabetic rats [12]. Leptin has been shown to be elevated in patients and mice with acute lung injury and resistance to leptin in diabetics may also be providing lung injury protection in diabetics [13].

Other lines of investigation focused on diabetic medications. Specifically, oral therapy with rosiglitazone has been associated with protection of lung damage in several animal models [14,15]. The postulated mechanism involves the activation of the Peroxisome proliferator-activated receptor (PPAR)-g, which functions as an important anti-inflammatory agent with a significant role in reducing lung injury. Insulin, also been shown to have effects beyond glycemic control. Insulin has been shown to be an immunomodulator through the leptin and nuclear factor $\mathrm{kB}$ pathways, producing alterations of pro and anti-inflammatory cytokines [16-18].

Even though a number of factors predispose to ARDS, there is rarity of factors that might be protective. The protective effect of diabetes in development of ARDS in patients with sepsis is fascinating and also raises many questions. Is the protective effect of diabetes limited to patients with sepsis and if so, why? It will be interesting to see if this protective effect also translates into improvement in clinical outcomes. Further insight into molecular mechanism and cross talks between diabetes and lung injury carries the potential for developing novel protective measures. However, decoding the clinical impact of molecular pathways would not be an easy task.

\section{Reference}

1. Zambon M, Vincent JL (2008) Mortality rates for patients with acute lung injury/ ARDS have decreased over time. Chest 133: 1120-1127.

2. Moss M, Guidot DM, Steinberg KP, Duhon GF, Treece P, et al. (2000) Diabetic patients have a decreased incidence of acute respiratory distress syndrome. Crit Care Med 28: 2187-2192.

3. Gong MN, Thompson BT, Williams P, Pothier L, Boyce PD, et al. (2005) Clinica predictors of and mortality in acute respiratory distress syndrome: potential role of red cell transfusion. Crit Care Med 33: 1191-1198.

4. Iscimen R, Cartin-Ceba R, Yilmaz M, Khan H, Hubmayr RD, et al. (2008) Risk factors for the development of acute lung injury in patients with septic shock: an observational cohort study. Crit Care Med 36: 1518-1522.

5. Honiden S, Gong MN (2009) Diabetes, insulin, and development of acute lung injury. Crit Care Med 37: 2455-2464.

6. Gajic O, Dabbagh O, Park PK, Adesanya A, Chang SY, et al. (2011) Early identification of patients at risk of acute lung injury: evaluation of lung injury prediction score in a multicenter cohort study. Am J Respir Crit Care Med 183: 462-470.

7. Ling PR, Smith RJ, Bistrian BR (2005) Hyperglycemia enhances the cytokine production and oxidative responses to a low but not high dose of endotoxin in rats. Crit Care Med 33: 1084-1089.

8. Nielson CP, Hindson DA (1989) Inhibition of polymorphonuclear leukocyte respiratory burst by elevated glucose concentrations in vitro. Diabetes 38 1031-1035.

9. Perner A, Nielsen SE, Rask-Madsen J (2003) High glucose impairs superoxide production from isolated blood neutrophils. Intensive Care Med 29: 642-645.

*Corresponding author: Ariel Modrykamien, Department of Medicine, Pulmonary Sleep and Critical Care Medicine Division, $601 \mathrm{~N}$, 30th Street, Suite 3820 Omaha, NE 68131, USA, Tel: (402) 449-4480; Fax: (402) 280-5256; E-mail arielmodrykamien@creighton.edu

Received November 21, 2012; Accepted November 23, 2012; Published November 26, 2012

Citation: Singla A, Modrykamien AM (2012) Diabetes Mellitus: Protective in Development of ARDS. J Pulmon Resp Med 2:e119. doi:10.4172/2161105X.1000e119

Copyright: $\odot 2012$ Singla A, wt al. This is an open-access article distributed under the terms of the Creative Commons Attribution License, which permits unrestricted use, distribution, and reproduction in any medium, provided the original author and source are credited. 
Citation: Singla A, Modrykamien AM (2012) Diabetes Mellitus: Protective in Development of ARDS. J Pulmon Resp Med 2:e119. doi:10.4172/2161105X.1000e119

10. Ramasamy R, Yan SF, Herold K, Clynes R, Schmidt AM (2008) Receptor for advanced glycation end products: fundamental roles in the inflammatory response: winding the way to the pathogenesis of endothelial dysfunction and atherosclerosis. Ann N Y Acad Sci 1126: 7-13.

11. Vanhorebeek I, De Vos R, Mesotten D, Wouters PJ, De Wolf-Peeters C, et al. (2005) Protection of hepatocyte mitochondrial ultrastructure and function by strict blood glucose control with insulin in critically ill patients. Lancet 365: 53-59.

12. Wright JK, Nwariaku FN, Clark J, Falck JC, Rogers T, et al. (1999) Effect of diabetes mellitus on endotoxin-induced lung injury. Arch Surg 134: 1354-1358.

13. Jain M, Budinger GR, Lo A, Urich D, Rivera SE, et al. (2011) Leptin promotes fibroproliferative acute respiratory distress syndrome by inhibiting peroxisome proliferator-activated receptor-y. Am J Respir Crit Care Med 183: 1490-1498.

14. Genovese T, Cuzzocrea S, Di Paola R, Mazzon E, Mastruzzo C, et al (2005) Effect of rosiglitazone and 15-deoxy-Delta12,14-prostaglandin J2 on bleomycin-induced lung injury. Eur Respir J 25: 225-234.
15. Liu D, Zeng BX, Zhang SH, Wang YL, Zeng L, et al. (2005) Rosiglitazone, a peroxisome proliferator-activated receptor-gamma agonist, reduces acute lung injury in endotoxemic rats. Crit Care Med 33: 2309-2316.

16. Dandona P, Aljada A, Mohanty P, Ghanim H, Hamouda W, et al. (2001) Insulin inhibits intranuclear nuclear factor kappaB and stimulates IkappaB in mononuclear cells in obese subjects: evidence for an anti-inflammatory effect? J Clin Endocrinol Metab 86: 3257-3265.

17. Hansen TK, Thiel S, Wouters PJ, Christiansen JS, Van den Berghe G (2003) Intensive insulin therapy exerts antiinflammatory effects in critically ill patients and counteracts the adverse effect of low mannose-binding lectin levels. J Clin Endocrinol Metab 88: 1082-1088.

18. Jeschke MG, Klein D, Bolder U, Einspanier R (2004) Insulin attenuates the systemic inflammatory response in endotoxemic rats. Endocrinology 145 4084-4093. 